\title{
Leishmania Game: tecnologia educativa para prevenção/ensino de leishmaniose visceral
}

\section{Leishmania Game: educational technology for prevention/teaching visceral leishmaniasis}

\author{
Monique Kerly Maia Fernandes ${ }^{1}$, \\ Diana Paula de Souza Rego Pinto Carvalho ${ }^{2}$
}

\begin{abstract}
Resumo
Introdução: a leishmaniose visceral, mais conhecida como calazar, é uma doença crônica causada por protozoários de Leishmania infantum e é uma doença caracterizada como endêmica no município de Pau dos Ferros, estado do Rio Grande do Norte. Dessa forma, a construção de uma tecnologia educativa pode ser uma ferramenta auxiliadora no processo de ensino e aprendizagem dos alunos. Objetivo: construir e validar conteúdo e aparência de jogo didático no ensino de leishmaniose visceral para alunos do ensino fundamental. Metodologia: trata-se de um estudo metodológico de abordagem quantitativa. $\mathrm{O}$ jogo foi confeccionado a partir de um esboço feito à mão pela autora $\mathrm{e}$ posteriormente entregue a um profissional responsável pelo design. Para validar o jogo, foi aplicado um protocolo de validação para 10 juízes que validaram o jogo de acordo com as expectativas curriculares e cognitivas dos alunos dos anos finais do ensino fundamental. Os dados coletados foram organizados no Microsoft ${ }^{\circledR}$ Excel $^{\circledR}$ e posteriormente apresentados em gráficos e tabelas para análise final. Resultados: no que diz respeito à média geral da tecnologia educacional, obteve-se média 4,6, que corresponde a $92 \%$ de concordância dos juízes. Dessa maneira, comprova-se que todos os itens da tecnologia educacional "Leishmania" foram validados pelos juízes obtendo média superior ao estipulado. Conclusão: todos os itens apresentados no protocolo de validação foram considerados adequados na avaliação dos juízes, o que garante a confiabilidade do instrumento para ser utilizado. Dessa forma, o jogo pode ser utilizado com segurança por professores para avaliar o conhecimento dos alunos acerca da leishmaniose visceral.
\end{abstract}

Palavras-chave: Doenças parasitárias. Ensino fundamental. Educação em saúde ambiental. Promoção da saúde.

\footnotetext{
${ }^{1}$ Mestrado em Ensino pelo Programa de Pós-graduação em Ensino da Universidade do Estado do Rio Grande do Norte (UERN), Pau dos Ferros, Rio Grande do Norte, Brasil. E-mail: monique_kerly@hotmail.com

${ }^{2}$ Doutorado em Enfermagem pelo Programa de Pós-graduação em Enfermagem da Universidade do Estado do Rio Grande do Norte, Natal, Rio Grande do Norte, Brasil. Professora Adjunta I do Curso de Graduação em Enfermagem da Universidade do Estado do Rio Grande do Norte, Pau dos Ferros, Rio Grande do Norte, Brasil.
} 


\begin{abstract}
Introduction: visceral leishmaniasis, better known as calazar, is a chronic disease caused by protozoa of Leishmania infantum and is a disease characterized as endemic in the municipality of Pau dos Ferros, state of Rio Grande do Norte. Thus, the construction of an educational technology can be a helping tool in the teaching and learning process of students. Objective: to construct and validate content and appearance of didactic game in the teaching of visceral leishmaniasis for elementary school students. Methodology: this was a methodological study with a quantitative approach. The game was handmade from a sketch by the author and delivered to a professional responsible for the design. To validate the game, an authentication protocol was applied to 10 judges who validated the game according to the curricular and cognitive expectations of students in the final years of elementary school. The collected data were organized in Microsoft ${ }^{\mathrm{TM}}$ Excel $^{\mathrm{TM}}$ and later presented in graphs and tables for final analysis. Results: regarding the overall average of educational technology, obtained a score of 4.6 , corresponding to $92 \%$ of the judges' agreement. Thus, it is proven that all items of educational technology "Leishmania" were validated by the judges obtaining an average higher than stipulated. Conclusion: all items presented in the validation protocol were considered adequate in the evaluation of the judges, which guarantees the reliability of the instrument to be used. Thus, the game can be safely used by teachers to assess students' knowledge about visceral leishmaniasis.
\end{abstract}

Keywords: Parasitic diseases. Elementary school. Environmental health education. Health promotion.

\section{Introdução}

Em meio aos desafios inseridos no ensino de Ciências, o modelo tradicional de ensino se destaca, no qual é comum encontrar professores que utilizam apenas deste método de ensino em sua prática docente, em que ele expõe o conteúdo de maneira na qual o aluno não exercita a sua criticidade, o que torna o ensino mecanizado e o aluno apto a reproduzir esse conhecimento através de avaliações. ${ }^{(1)}$

Admite-se que a educação seja a chave para uma mudança de mentalidades e atitudes na sociedade. A escola é o espaço privilegiado para concretizar um conjunto de comportamentos e atitudes que contribuem para a descoberta de soluções para o desenvolvimento e à sustentabilidade. ${ }^{(2)}$

Dessa maneira, se faz mais que necessário a utilização de métodos e ferramentas que auxiliem o ensino e aprendizagem dos alunos, de forma que eles possam compreender o ambiente à sua volta a fim de exercitar a sua criticidade e aprender de forma significativa.

Trata-se de uma teoria que proporciona o uso de estratégias que abordam a interação de novos conhecimentos com os conhecimentos previamente estabelecidos a partir da interação com um determinado subsunçor - adquire novos significados capazes de servir como âncora para novas aprendizagens significativas e tem como características principais a não arbitrariedade, entendida como a relação lógica e relevante entre a ideia nova e as já existentes, e não substantiva, ou seja, o aluno adquire capacidade de expressar o novo conhecimento com suas próprias palavras. ${ }^{(3)}$

Essa estratégia de ensino tem como objetivo trazer um significado para o que o aluno aprende em sala de aula, não apenas um conteúdo no qual ele vai depositar como resposta em uma avaliação, mas um conteúdo com significado prático na sua vida pessoal e social, e o desperta a refletir sobre o ambiente à sua volta de forma crítica.

Em meio a tantas estratégias didáticas para auxiliar o aluno no processo de ensino e aprendizagem, os jogos, que antes eram vistos somente como entretenimento, passaram a ser uma estratégia lúdica de aprendizagem. $\mathrm{O}$ uso de jogos em sala de aula é considerado uma estratégia eficaz, pois é uma alternativa para qual o ensino tradicional já é suficiente. ${ }^{(4-5)}$

É possível perceber que os jogos auxiliam não somente no significado do conteúdo abordado em 
sala de aula, mas também no seu desenvolvimento cognitivo e social, pois contribui para a interação social do educando e sua relação com o cotidiano de acordo com o assunto abordado no jogo e a forma como o professor vai construir e aplicar este tipo de material.

Os jogos competitivos trabalham regras sociais, que auxiliam o aluno na tomada de decisões, a lidar com vitórias e derrotas, a se relacionar e competir com os colegas. Todos esses fatores permitem que o aluno se torne apto a relacionar-se com o mundo e as transformações que ocorrem à sua volta. ${ }^{(6)}$

Além dos benefícios citados anteriormente, os jogos proporcionam uma interação maior entre aluno e professor, na qual o professor vai ser o mediador das informações que foram inseridas no jogo e tornar-se um facilitador do processo de aprendizagem. Desse modo, o aluno pode aprender conteúdos de grande relevância social como temas relacionados à prevenção de doenças, como, por exemplo, a leishmaniose visceral (LV), de forma lúdica e divertida.

Leishmaniose visceral, mais conhecida como calazar, é uma doença crônica causada por parasitos pertencentes ao gênero Leishmania e apresenta aspectos clínicos e epidemiológicos diversos e característicos para cada região. A epidemiologia depende das características das espécies de parasitas e flebotomíneos, das características dos locais onde ocorre a transmissão, da exposição da população ao parasita e do comportamento humano. Existem cerca de 70 espécies de animais que são reservatórios naturais de Leishmania, incluindo o homem. ${ }^{(7-8)}$ No Brasil, as leishmanioses endêmicas se encontram em todos os estados, no entanto, são enfermidades ainda negligenciadas. ${ }^{(9)}$

A leishmaniose visceral (LV) é uma doença caracterizada como endêmica (que se manifesta numa determinada região) no município de Pau dos Ferros, no estado do Rio Grande do Norte, o que justifica a importância de abordar este tema, especialmente nas escolas, pois os alunos terão conhecimento para que eles possam se prevenir contra a doença.
O município de Pau dos Ferros está situado no interior do Rio Grande do Norte. Localiza-se no Oeste Potiguar que fica a aproximadamente $392 \mathrm{~km}$ de Natal, capital do estado. Pau dos Ferros possui população estimada de 30.452 habitantes e é uma cidade considerada polo para as cidades vizinhas. Os dados disponibilizados pelo SINAN-SUVIGE/ CPS/SESAP-RN ${ }^{(10)}$ mostraram que no período de 2014 à $22^{\mathrm{a}}$ semana de 2019 foram notificados 23 novos casos de LV, tendo, desses, 19 casos confirmados. No ano de 2018 houve dois óbitos, e até a $22^{\mathrm{a}}$ semana de 2019 houve um caso de óbito confirmado no município. Não houve atualização dos dados fornecidos no sistema do DATASUS com dados do ano de 2019 completo. Destaca-se, portanto, a importância de trabalhar a temática LV com a população para evitar novos casos.

Conhecer as características da doença no País é importante, pois torna útil o planejamento de estratégias de prevenção e controle que podem auxiliar na diminuição do número de casos e de mortalidade, além de auxiliar a organização de políticas públicas, que, direcionadas à população mais afetada, pode torná-las mais eficazes; porém, ainda há poucos trabalhos publicados sobre as características da LV no Brasil. ${ }^{(11)}$

Dessa forma, a construção de um jogo pode ser uma ferramenta auxiliadora no processo de ensino e aprendizagem dos alunos, não somente nas aulas de Ciências, mas que seja uma forma lúdica de alertar os alunos para este problema. $\mathrm{O}$ trabalho tem como objetivo construir e validar conteúdo e aparência de jogo didático no ensino de LV para alunos do ensino fundamental.

\section{Material e Método}

Trata-se de um estudo metodológico com abordagem quantitativa para construção e validação de conteúdo de jogo didático para apoio ao ensino da temática leishmaniose visceral aos estudantes do ensino fundamental.

O presente estudo foi submetido ao Comitê de Ética em Pesquisa da Universidade do Estado do Rio Grande do Norte (CEP - UERN) e obteve 
como situação do parecer aprovado $\mathrm{n}^{\circ} 3.735 .091$ de 29/11/2019 para a realização da pesquisa tendo sido respeitados os princípios éticos em todas as etapas da pesquisa de acordo com os preceitos éticos estabelecidos pela Resolução no 466/2012, do Conselho Nacional de Saúde (CNS).

O jogo foi confeccionado a partir de um esboço feito à mão pela autora e posteriormente entregue a um aluno do curso de Informática do Instituto Federal de Educação, Ciência e Tecnologia (IFRN), do campus de Pau dos Ferros, que fez o design.

Os pinos (Figura 1) foram confeccionados em biscuit no formato de promastigota metacíclica (forma infectante do protozoário), nas cores azul, vermelho, amarelo, verde e branco, em suas respectivas bases. Os dados foram reaproveitados de jogos de tabuleiro já existentes.

Figura 1 - Pinos da tecnologia educacional "Leishmania".

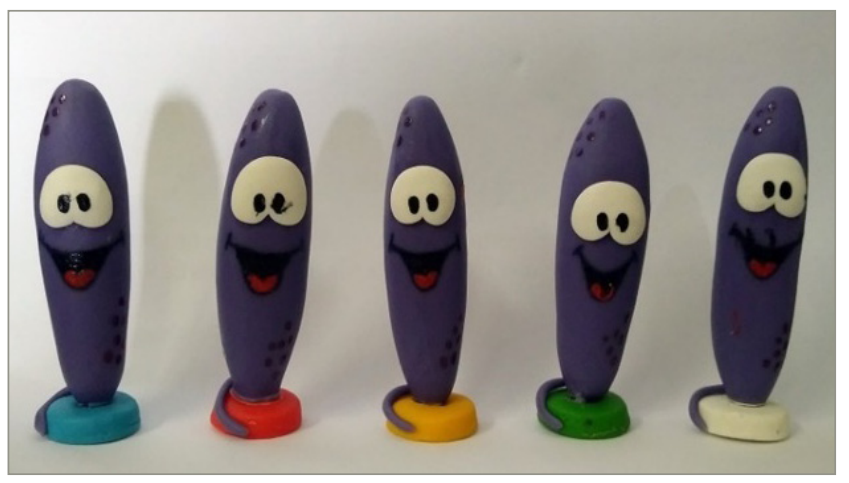

Fonte: Autoras

O tabuleiro do jogo (Figura 2) contém 35 casas, nas quais os jogadores podem percorrer; estão distribuídas casas da cor vermelha, que correspondem às cartas-perguntas, casas da cor azul, que correspondem às cartas de prevenção/ infecção (Figura 3) e casas da cor esverdeada, que correspondem à quarentena ou promastigota metacíclica, que leva o jogador à quarentena.

Figura 2 - Tabuleiro da tecnologia educacional "Leishmania".

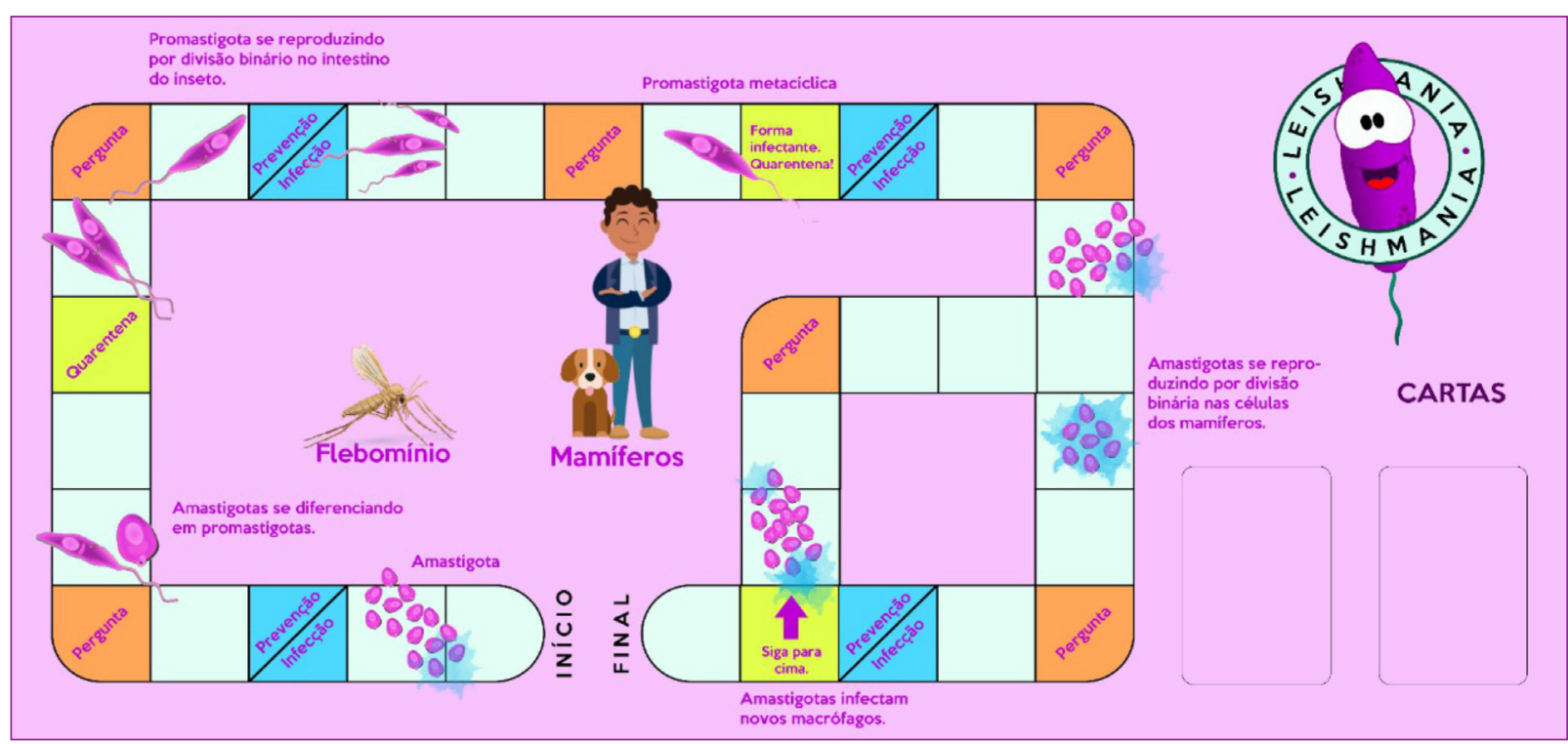

Fonte: Autoras 
O jogo foi pensado como uma alternativa didática que pudesse estimular a conscientização dos alunos acerca da LV e tem como objetivo contribuir para a formação social dos alunos, no momento em que os mesmos assumem o lugar do protozoário, conhecem o ciclo de vida e a forma como ele se transmite, nos hospedeiros e quais os sintomas que ele causa. Tudo isso foi pensado para que o aluno tomasse conhecimento de todas as etapas decorrentes da doença e dessa forma pudesse adquirir atitudes que ajudassem na prevenção e na disseminação do conhecimento.

Figura 3 - Modelo de cartas-perguntas e cartas de infecção/prevenção da tecnologia educacional "Leishmania"
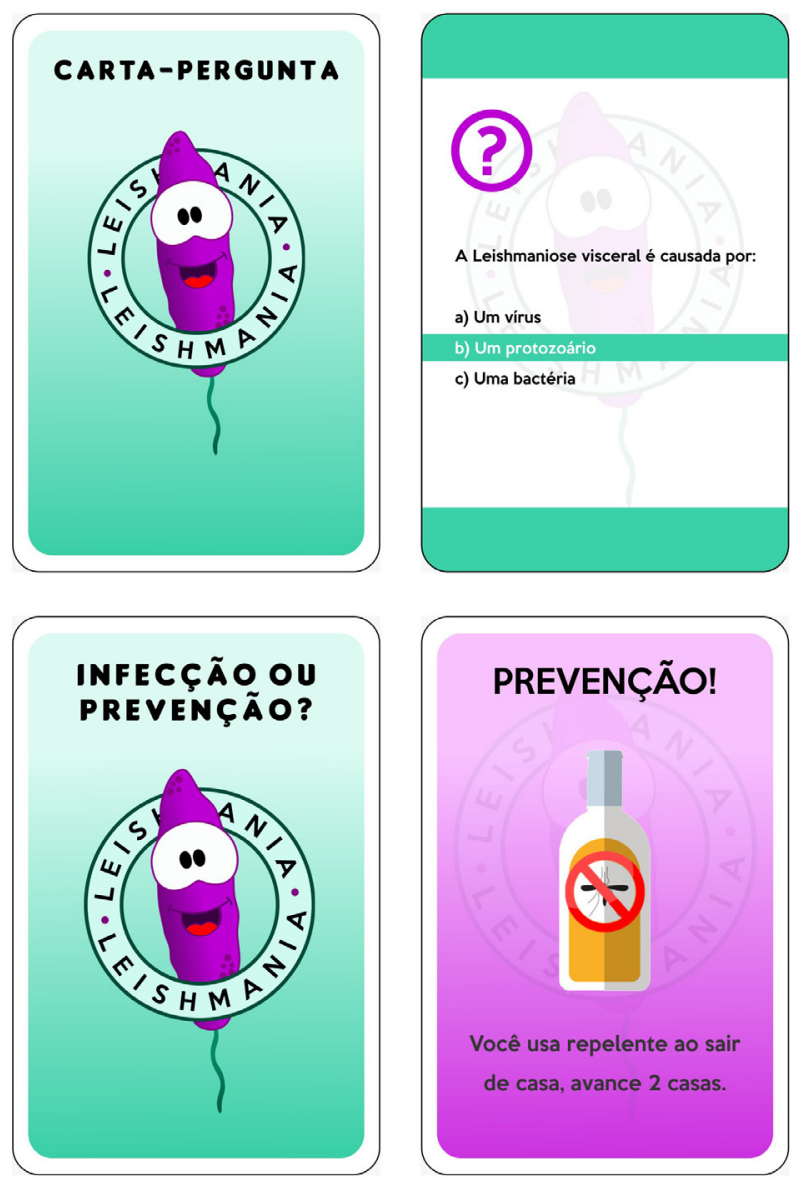

Fonte: Autoras

Como os livros didáticos apresentam poucas informações sobre a doença $\mathrm{LV}$, as cartas-perguntas foram construídas mediante embasamento teórico do site do Ministério da Saúde (MS), do livro Parasitologia humana, $13^{\text {a }}$ edição, de Neves et al. (2016) e do livro Parasitologia, $4^{\mathrm{a}}$ edição, de Rey
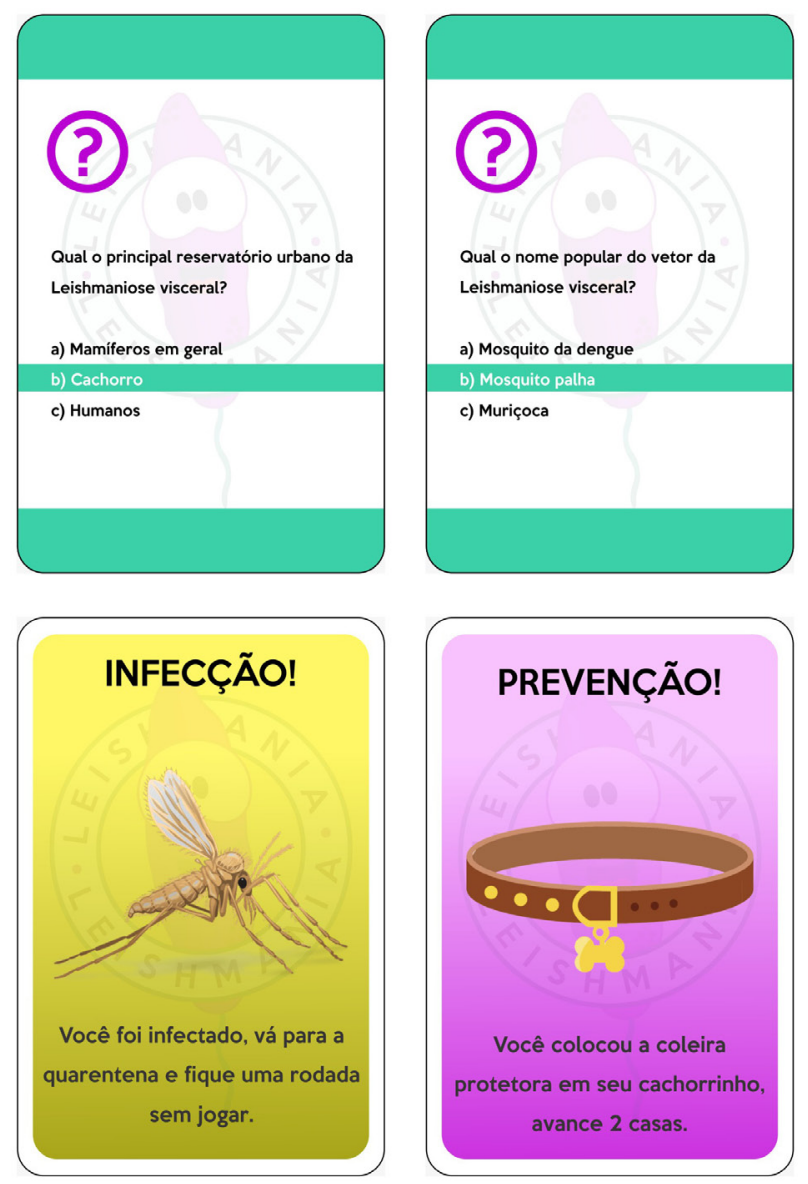

(2018), e colocadas em uma linguagem adaptada para a faixa etária dos alunos do $8^{\circ}$ e do $9^{\circ}$ ano do ensino fundamental.

Para as regras do jogo foi confeccionada uma cartilha (Figura 4) para que o mediador e os jogadores saibam como a partida funciona. 
Figura 4 - Cartilha de regras do jogo "Leishmania".

\section{SOBRE O JOGO}

Leishmania é uma tecnologia educativa do tipo jogo de tabuleiro de cunho educacional, fruto do trabalho de dissertação do Programa de Pós-Graduação em Ensino - PPGE, da Universidade do Estado do Rio Grande do Norte - UERN. Nele encontram-se as caracteristicas da doença como: sintomas, transmissão, ciclo de vida e prevenção. $O$ jogo apresenta um layout original com a temática Leishmaniose visceral, uma doença crônica mais conhecida popularmente como Calazar que é transmitida por um protozoário. O jogo tem como objetivo despertar o interesse dos alunos acerca da doenca e subsidiar o ensino por meio de uma abordagem ativa e interativa para que os mesmo passem a serem disseminadores de conhecimento. $O$ jogo também é uma ferramenta lúdica para o professor trabalhar em sala de aula como material complementar.

Autoria: Monique Kerly Maia Fernandes

Coordenação: Prof. Dra. Diana Paula de Souza Rego Pinto Carvalho

Produção Técnica

Desenvolvimento e criação: Monique Kerly Maia Fernandes

Design: Sadrak Lyon Dantas Pontes

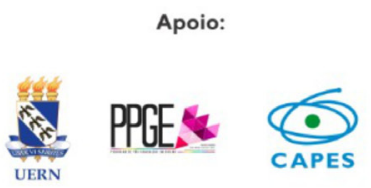

\section{REGRAS DO JOGO}

Ojogo pode conter de dois até cinco jogadores.

INICIO DO JOGO-Osjogadores devem escolher um protozoário de acordo com a sua cor e decidir a sequência de jogada com o dado. Quem obtiver o maior número no dado inicia a partida.

$O$ jogador 1 lança o dado e anda o número de casas sorteado. Ao parar numa casa pergunta, o jogador 2 deve pegar uma carta-pergunta e ler para o jogador 1 e assim sucessivamente. Caso ele acerte a pergunta, jogará o dado novamente e continuará caminhando, mas ao errar permanecerá no mesmolugar e aguardará a próxima rodada.

Quandoojogador parar em uma casa infecção/prevenção deverá puxar uma carta e ler o que a sorte o reserva. Caso seja uma carta de prevenção, o jogador terá um número específico de casas para andar, porém, caso a carta seja de infecção, ojogador deverá voltar o número de casas especificadasna carta.

Quando o jogador parar na casa Promastigota metacíclica será encaminhado para a Quarentena e perderá a vez por uma rodada. 0 jogador também vai para quarentena quando parar na casa Quarentena ou puxar uma carta infecção/prevenção e ela o encaminhar para lá.

Ao parar na casa Amastigotas infectam novos macrófagos o jogador, deverá jogar o dado e ver o número de casas que deve caminhar voltando novamente para o ciclo de vida nos mamíferos, tendo a possibilidade de cair em uma casa pergunta.

IMPORTANTE: O jogador retornará ao ciclo de vida nos mamiferos sempre que cair na casa Amastigotas infectam novos macrófagos, mesmo quejá tenha passado por ela uma vez.

FIM DE JOGO - Ganhará a partida o jogador que conseguir completar o ciclo de vida do parasito primeiro.

Fonte: Autoras

Foi realizado um levantamento do número de professores pertencentes às escolas públicas e particulares do município de Pau dos Ferros, que posteriormente foram classificados como juízes. Para validação da tecnologia educacional foram estabelecidos alguns critérios para selecionar os juízes: (1) ser professor de Ciências ou Biologia; (2) com atuação na área por um período igual ou superior a um ano; (3) atuantes no município de Pau dos Ferros; e (4) ter interesse expresso em colaborar com o estudo. Os juízes foram os responsáveis por avaliar os itens propostos na tecnologia educativa.

Para isso, foi produzido um protocolo de validação, o qual possuía cinco itens: objetivos; estrutura e apresentação; cartas-perguntas; cartas de prevenção/infecção; e relevância. Todos os itens apresentavam um número $\mathrm{X}$ de afirmativas que os juízes iriam avaliar. Ao todo, o protocolo de validação continha 81 afirmativas a serem avaliadas.

Cada afirmativa possuía uma escala Likert com os itens: (1) discordo totalmente; (2) discordo parcialmente; (3) não discordo, nem concordo; (4) concordo parcialmente; e (5) concordo totalmente; seguindo a vertente de Teoria de Resposta ao Item (TRI), de acordo com Pasquali (2009).

Para avaliar o grau de concordância do conteúdo do jogo foi utilizado o Índice de Validade de Conceito (IVC = número de respostas válidas/ número total de respostas) e a taxa aceitável de concordância deve ser igual ou superior a $80 \%$. E para avaliar a validade do conteúdo da tecnologia educacional foi realizada a técnica Delphi, também denominada de conferência de Delphi, a qual consiste na análise inicial de um questionário/ instrumento pelo grupo respondente e análise da concordância dos mesmos.

\section{Resultados}

O produto deste artigo foi um jogo de tabuleiro intitulado "Leishmania", nome em alusão à Leishmania, gênero ao qual o parasita pertence. 
A tecnologia educacional foi pensada como uma estratégia metodológica para auxiliar os professores em sala de aula, ao abordar o conteúdo de parasitologia, especificamente sobre LV. O jogo se desenvolve no ciclo de vida do parasita como uma alternativa que venha facilitar a compreensão, já que este é um dos conteúdos mais difíceis de aprender sobre a doença por apresentar muitos nomes técnicos. Dessa forma, o tabuleiro explica didaticamente todo o ciclo de vida, desde sua entrada no inseto vetor, como também sua reprodução no interior dos mamíferos após a infecção.

Estabelecidos os critérios para seleção dos juízes, foi realizado um levantamento do número de professores de Ciências e de Biologia pertencentes às escolas públicas e privadas do município de Pau dos Ferros, totalizando 10 escolas e 20 professores.

Após o levantamento de dados, o contato dos professores foi disponibilizado pelos diretores das respectivas escolas e o primeiro contato com os mesmos se deu via aplicativo de mensagem WhatsApp, no qual foram esclarecidos objetivos, etapas e importância da colaboração dos mesmos para a pesquisa. Dos 20 professores, apenas 12 concordaram em participar.

Do total de professores que concordaram em participar da pesquisa, apenas 10 atenderam a todos os critérios de seleção. Para validar o jogo, foi aplicado aos professores um protocolo de validação, em que eles deveriam avaliar os objetivos, estrutura e apresentação, conteúdo das cartas-perguntas, cartas de infecção/prevenção e relevância da tecnologia educativa. O protocolo foi entregue de forma presencial e impressa aos professores no período de 5 a 9 de dezembro de 2019, com prazo máximo de 15 dias para entrega.

Os professores foram codificados de 1 a 10 de acordo com a ordem de recebimento dos protocolos. Vale ressaltar que os juízes não podiam se identificar. Os juízes apresentaram perfil com idade entre 24 e 55 anos, e o júri foi composto por 6 juízes do sexo feminino e 4 do sexo masculino.

De acordo com a formação acadêmica, 6 juízes possuem graduação em Ciências Biológicas, 3 em Química e 1 em Letras, com tempo médio de formação de nove anos e tempo médio de exercício profissional de sete anos. Em relação à titulação, 9 juízes possuem especialização e 1 possui mestrado.

Os dados obtidos do protocolo de validação foram tabulados em planilha no Microsoft ${ }^{\circledR}$ Excel $^{\circledR}$ 2010 e organizados em tabela, na qual mostra o Índice de Validade de Conceito (IVC = número de respostas válidas/número total de respostas) atribuído pelos juízes em todos os itens apresentados no protocolo de validação e sua média final, apresentados no quadro a seguir (Quadro 1).

Quadro 1 - Avaliação quantitativa dos juízes da tecnologia educacional "Leishmania".

\begin{tabular}{|c|c|}
\hline \multicolumn{1}{|c|}{ Itens avaliados } & $\begin{array}{c}\text { IVC } \\
\left(\mathbf{n}^{\mathbf{0}} \text { de respostas válidas/ }\right. \\
\mathbf{n}^{\mathbf{0}} \text { total de respostas) }\end{array}$ \\
\hline $\begin{array}{c}\text { 1 - Objetivos: referem-se a propósitos, metas ou fins que se deseja atingir } \\
\text { com a utilização da tecnologia educacional. }\end{array}$ & $283 / 60=4,7$ \\
\hline $\begin{array}{c}\text { 2 - Estrutura e apresentação: referem-se à forma de apresentar as orientações. } \\
\text { Isso inclui organização geral, estrutura, estratégia de apresentação, coerência } \\
\text { e formatação. }\end{array}$ & $668 / 150=4,5$ \\
\hline $\begin{array}{l}\text { 3 - Cartas-perguntas: para avaliar se as perguntas estão adequadas ao nível } \\
\text { do público-alvo. }\end{array}$ & $1.649 / 350=4,7$ \\
\hline $\begin{array}{l}\text { 4 - Cartas prevenção/infecção: avaliar se as afirmações estão coerentes para } \\
\text { o público-alvo. }\end{array}$ & $879 / 200=4,4$ \\
\hline $\begin{array}{c}\text { 5 - Relevância: refere-se às características que avaliam o grau de significação } \\
\text { da tecnologia educacional. }\end{array}$ & $231 / 50=4,6$ \\
\hline Média final & 4,6 \\
\hline
\end{tabular}

Fonte: Autoras 
Os objetivos da tecnologia educacional "Leishmania" obtiveram média equivalente a 94\% do IVC, a qual confirma que o propósito da criação do jogo foi validado. Com relação à estrutura e apresentação da tecnologia educacional, o IVC foi igual a $90 \%$, o que valida a forma como o jogo foi apresentado. $\mathrm{O}$ uso de ilustrações e diversidade de cores torna a tecnologia educacional mais atrativa ao público-alvo, que é caracterizado por alunos dos anos finais do ensino fundamental. A forma como as informações são apresentadas no jogo é considerada o cartão de visita, o que instiga a curiosidade do aluno e o faz se sentir estimulado a jogar.

O item cartas-perguntas da tecnologia educacional apresentou IVC igual a 94\%, percentual que confirma a adequação do conteúdo ao públicoalvo. As perguntas foram criadas com a intenção de estimular o aluno a buscar mais conhecimento, pois quanto maior o seu conhecimento sobre o conteúdo, maiores são suas chances de responder as perguntas corretamente e percorrer no tabuleiro a fim de chegar ao final antes dos seus adversários. Essa competitividade acaba por se tornar um estímulo para a busca de novos conhecimentos.

Com relação às cartas infecção/prevenção, o IVC foi igual a $88 \%$; estas apresentaram o menor percentual de validação de todos os itens apresentados no protocolo de validação. As cartas de prevenção/infecção foram criadas no intuito de fazer os alunos compreenderem as consequências de quando não se previnem contra a leishmaniose visceral; dessa forma, os alunos acabam se conscientizando e colocando em prática as medidas de prevenção apresentadas no jogo.

Alguns itens apresentaram sugestões de melhoria por parte dos juízes, que foram atendidas de acordo com o quadro a seguir (Quadro 2).

Quadro 2 - Sugestão de alteração de itens por juízes da tecnologia educacional "Leishmania".

\begin{tabular}{|c|c|c|c|}
\hline Juiz & Item & Sugestão & Alteração \\
\hline 2 & Alterar cartas-perguntas. & $\begin{array}{l}\text { Seria interessante padronizar as } \\
\text { cartas-perguntas com verdadeiro } \\
\text { ou falso, algumas tem "sim ou não". }\end{array}$ & A alteração foi realizada. \\
\hline 2 e 10 & $\begin{array}{l}4.2 \text { - Sua mãe te chamou } \\
\text { para almoçar e você não } \\
\text { lavou as mãos, volte } 3 \\
\text { casas. }\end{array}$ & $\begin{array}{l}\text { Não consigo fazer o link com } \\
\text { a doença descrita. } \\
\text { Poderia ter algo relacionado à } \\
\text { vacinação do cão por campanhas } \\
\text { do governo. }\end{array}$ & $\begin{array}{l}\text { A carta foi substituída por: } \\
\text { "o governo fez campanha de } \\
\text { vacinação contra a leishmaniose } \\
\text { para cães e você não vacinou o } \\
\text { seu cachorrinho, volte } 4 \text { casas". }\end{array}$ \\
\hline 3 & $\begin{array}{l}4.3 \text { - Você não limpou o } \\
\text { quintal e seu cachorro foi } \\
\text { infectado, volte } 2 \text { casas. }\end{array}$ & $\begin{array}{l}\text { Acho que a consequência dessa } \\
\text { atitude é mais grave, poderia voltar } \\
\text { mais casas. }\end{array}$ & $\begin{array}{l}\text { Você não limpou o quintal e seu } \\
\text { cachorro foi infectado, passe a } \\
\text { vez para o jogador seguinte. }\end{array}$ \\
\hline 8 & $\begin{array}{l}4.15 \text { - Você usa inseticida } \\
\text { na sua casa regularmente, } \\
\text { avance } 3 \text { casas. }\end{array}$ & $\begin{array}{l}\text { O termo "inseticida" está inadequado, } \\
\text { pois faz mal ao meio ambiente. }\end{array}$ & $\begin{array}{l}\text { Você usa repelente na sua casa } \\
\text { regularmente, avance } 3 \text { casas. }\end{array}$ \\
\hline
\end{tabular}

Fonte: Autoras

Vale destacar que o item 4, correspondente às cartas de prevenção/infecção, foi o único que apresentou sugestões de alterações significativas por parte dos avaliadores. Já com relação ao item 3 , correspondente às cartas-perguntas, foi sugerida uma padronização das questões que apresentavam perguntas de verdadeiro ou falso, pois algumas cartas apresentavam sim ou não como alternativas. O último item avaliado foi sobre a relevância da tecnologia educacional (item 5), que apresentou IVC igual a $92 \%$.

Ao terminar de avaliar o protocolo, alguns juízes fizeram considerações positivas sobre a tecnologia educacional: 
Muito válido o seu trabalho.

Achei criativo.

O jogo está incrivel e adoraria poder trabalhálo em sala.

A tecnologia educacional obteve média igual a 4,6 - que corresponde a $92 \%$ de concordância dos juízes. Dessa maneira, comprova-se que todos os itens da tecnologia educacional "Leishmania" foram validados pelos juízes, que teve média superior ao estipulado. Ao pensar pelo âmbito social, a tecnologia educativa pode proporcionar a conscientização populacional, pois os alunos se tornam disseminadores de conhecimento e dessa forma passam a estimular seus pais e vizinhos a combaterem a doença.

\section{Discussão}

As etapas de construção e validação de uma tecnologia educacional consistem em um processo fundamental, que precisa de técnicas adequadas, sem as quais podem ocasionar na produção de um material com objetivos educacionais efetivos ausentes. $^{(5)}$

Um jogo sozinho não tem a capacidade de transformar a prática docente, mas pode ser considerado um recurso no qual os professores que procuram estratégias diferenciadas de ensino possam despertar na sua prática o interesse dos alunos perante as mudanças que ocorrem no ensino. ${ }^{(6)}$ Intervenções lúdicas são muito importantes no processo de ensino e aprendizagem dos alunos. ${ }^{(12)}$

O jogo educativo proporciona um ambiente de aprendizagem que incorpora conteúdos de forma espontânea, no qual estimula os estudantes e permite a construção do conhecimento para um futuro no qual a aprendizagem será mais técnica e complexa. ${ }^{(13)}$

O professor tem um papel fundamental na formação crítica dos alunos no que diz respeito à tomada de decisões e a conviver em sociedade; os jogos tem a vantagem de apoiar nesse aspecto, pois o professor será o mediador do conhecimento e os alunos se colocam nas posições de seres pensantes capazes de tomar decisões a fim de resolver o problema, como, por exemplo, as questões que estão presentes no jogo que podem ser associadas ao contexto dos alunos.

A ludicidade dos instrumentos de aprendizagem proporciona estímulos que geram interesse nos alunos por fazerem parte do seu universo cognitivo, que auxilia na formação da sua personalidade e construção do conhecimento, no qual cabe ao docente conduzir e avaliar a aprendizagem, ensinar a aprender e buscar capacitação para a sua prática em sala de aula. ${ }^{(14)}$

Os jogos podem contribuir bastante para o processo de ensino e aprendizagem, principalmente quando estão relacionados à saúde, pois proporcionam debates sobre as ações relacionadas à prevenção, além de promover um contato maior dos alunos com os professores, o que torna a aprendizagem mais atraente para ambos. ${ }^{(15)}$

Nas aulas de Ciências e de Biologia, jogos que abordam educação em saúde proporcionam uma melhor compreensão dos conteúdos, que auxilia no processo de ensino e aprendizagem e, consequentemente, uma melhoria na qualidade de vida dos estudantes proveniente da mudança de comportamento. ${ }^{(16)}$

Jogos que abordam educação em saúde são vistos como materiais complementares ao ensino que auxiliam na melhoria da qualidade de vida dos alunos, pois no momento da partida eles adquirem mais conhecimento sobre uma determinada doença e a sua prevenção, o que vai refletir nas suas práticas diárias fora da sala de aula.

Dessa maneira, a utilização deste tipo de ferramenta, seja como entretenimento/recreação ou artefato de aprendizagem, apresenta grande potencial ao introduzir conceitos importantes nos jogos que podem impactar positivamente a formação intelectual dos alunos. ${ }^{(17)}$

Questões relacionadas à saúde precisam ser abordadas em sala de aula, nas quais os professores devem assumir a responsabilidade de propor atividades que contribuam com o desenvolvimento do pensamento crítico que torne o aluno capaz de optar por hábitos de vida mais saudáveis. ${ }^{(18)}$ 
Por se caracterizar uma doença endêmica no município de Pau dos Ferros, a tecnologia educativa sobre a $L V$ vai proporcionar conhecimento aos alunos para que eles possam se prevenir contra a doença. Faz-se necessário a compreensão sobre os sintomas da leishmaniose, bem como sua forma de transmissão e, principalmente, sua forma de prevenção com o objetivo de reduzir a incidência de novos casos. ${ }^{(19)}$

Dessa forma, faz-se necessário a utilização de estratégias didáticas que abordem temas como LV a fim de formar cidadãos críticos e capazes de serem responsáveis e modificar o ambiente onde vivem.

\section{Conclusão}

Com a elaboração do estudo foi possível construir e validar uma tecnologia educacional para apoiar o ensino da temática LV (leishmaniose visceral) aos estudantes do ensino fundamental, que atende aos objetivos do trabalho.

Todos os itens apresentados no protocolo de validação foram considerados adequados na avaliação dos juízes, o que garante a confiabilidade do instrumento para ser utilizado com segurança em sala de aula, a fim de proporcionar conhecimento acerca da leishmaniose visceral.

A criação deste jogo foi uma tarefa árdua, pois muitas pesquisas foram feitas para aprofundamento teórico sobre a doença, construção e validação de jogos e exclusividade do trabalho realizado, pois não foi possível encontrar nenhum trabalho que tenha utilizado jogos sobre LV e isso foi um fator limitante para as discussões do trabalho.

Pretende-se futuramente realizar trabalhos que avaliem a aplicabilidade e a efetividade da tecnologia educacional.

\section{Referências}

1 Castro BJ, Costa PCF. Contribuições de um jogo didático para o processo de ensino e aprendizagem de Química no Ensino Fundamental segundo o contexto da Aprendizagem Significativa. Reiec. 2011;6(2):1-13.
2 Ferreira CM. Educação ambiental nas escolas [dissertação]. Porto: Instituto Politécnico do Porto; 2017.

3 Moreira MA. Aprendizagem significativa: a teoria e textos complementares. São Paulo: Editora Livraria de Física; 2011.

4 Gallão MI, Castelo AOC, Teófilo FBS, Rocha AM, Andrade ARC, Martins ABS, et al. Biomas: estudo através de jogo didático. Rev da SBEnBIO. 2014;1(7):213-23.

5 Salvador PTCO, Mariz CMS, Vítor AF, Ferreira MA Jr, Fernandes MID, Martins JCA, et al. Validation of virtual learning object to support the teaching of nursing care systematization. Rev Bras Enferm [Internet]. 2018;71(1):11-9. doi: 10.1590/0034-7167-2016-0537.

6 Santos GS, Oliveira MFA. O jogo como recurso didático para o ensino de nutrição: na trilha dos nutrientes. Rev Ensino, Saude Ambient. 2018;11(3):1-27.

7 Neves DP. Parasitologia humana. 13a. ed. São Paulo: Editora Atheneu; 2016.

8 Organización Mundial de la Salud (OMS). Leishmaniasis [internet]. 2020 [cited 2020 ago 14]. Available from: https://www.who.int/es/ news-room/fact-sheets/detail/leishmaniasis

9 França VH. As leishmanioses em escolas do ensino básico de Divinópolis, MG: análise de livros didáticos de ciências e biologia e das representações sociais de professores sobre o tema [dissertação]. Belo Horizonte (MG): Centro de Pesquisas René Rachou; 2011.

10 Sistema de Informação de Agravos de Notificação (Sinan). Leishmaniose visceral - Casos confirmados notificados no sistema de informação de agravos de notificação - Rio Grande do Norte. [Internet] 2019. [citado 2019 ago 08]. Disponível em: http://tabnet.datasus.gov. $\mathrm{br} /$ cgi/deftohtm.exe?sinannet/cnv/leishvRN. def

11 Lemos MDA, Sousa OH, Silva ZSSB. Perfil da leishmaniose visceral no Brasil: uma revisão bibliográfica. J Business Techn. 2019;9(1):93114. 
12 Bragagnollo GR, Santos TS, Fonseca REP, Acrani M, Castelo Branco MZP, Ferreira BR. Playful educational intervention with schoolchildren on intestinal parasitosis. Rev Bras Enferm. 2019;72(5):1203-10. doi: 10.1590/ 0034-7167-2017-0551.

13 Sena S, Schmiegelow SS, Prado GMBC, Sousa RPL, Fialho FAP. Aprendizagem baseada em jogos digitais: a contribuição dos jogos epistêmicos na geração de novos conhecimentos. Rev Renote. 2016;14(1):1-11. doi: 10.22456/1679-1916.67323.

14 Lima e Menezes GP. A importância dos jogos na produção de texto. Só Pedagogia [Internet]. 2017 [citado 2020 mar 20]. Disponível em: https://www.pedagogia.com.br/artigos/ jogostexto/index.php

15 Romeiro SS, Paula PL, Rosa FM. O uso de jogos didáticos no ensino de doenças intestinais causadas por protozoários Entamoeba histolytica e Giardia duodenalis. Rev. Bras. Zoociências. 2019;20(2):1-11.

16 Sousa TN, Chupil H. A contribuição dos jogos lúdicos na aprendizagem de ensino da parasitologia em ciências e biologia. Rev Uningá [Internet]. 2019 [citado 2020 maio 20];56(1):47-57. Disponível em: http://revista. uninga.br/index.php/uninga/article/view/2127

17 Santana PFC, Fortes DX, Porto RA. Jogos digitais: a utilização no processo ensino aprendizagem. Rev Cient da FASETE [Internet]. 2016 [citado 2020 maio 20]1:21829. Disponível em: https://www.unirios.edu. $\mathrm{br} /$ revistarios/media/revistas $/ 2016 / 10 /$ jogos digitais_a_utilizacao_no_processo_ensino_ aprendizagem.pdf

18 Mussi RFF, José HPM, Azevedo DP, Amorim AM, Petroski EL. O ensino da antropometria na escola: uma proposta na educação em saúde. Rev Cenas Educ. 2019;(1):14-28.

19 Santos DB, Saldanha IM, Fernandes LS, Coelho SHA, Pinto ACMD. A importância do esclarecimento e prevenção da leishmaniose [Internet]. 2017 [citado 2020 maio 20]. Disponível em: http://publicacoesacademicas. unicatolicaquixada.edu.br/index.php/mice/ article/view/1769 
Fernandes, M. K. M.; Carvalho, D. P. S. R. P. 